\title{
Successful weight loss maintenance: A systematic review of weight control registries
}

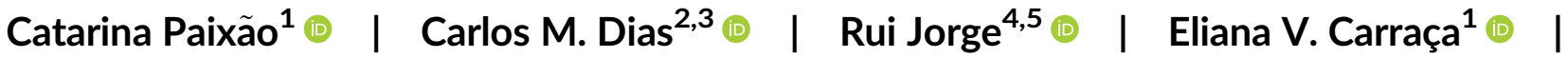

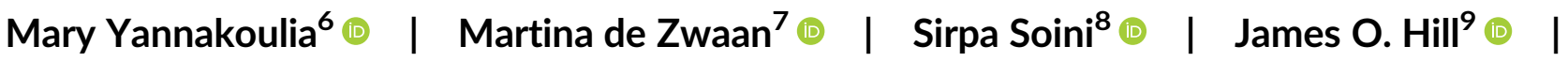 \\ Pedro J. Teixeira ${ }^{1}$ () | Inês Santos ${ }^{1,10}$ (1)
}

${ }^{1}$ Centro Interdisciplinar para o Estudo da Performance Humana, Faculdade de Motricidade Humana, Universidade de Lisboa, Cruz Quebrada Dafundo, Portugal

${ }^{2}$ Centro de Investigação em Saúde Pública (CISP), NOVA-Escola Nacional de Saúde Pública, Lisbon, Portugal

${ }^{3}$ Departamento de Epidemiologia, Instituto Nacional de Saúde Doutor Ricardo Jorge, Lisbon, Portugal

${ }^{4}$ Centro de Investigação Interdisciplinar Egas Moniz (CiiEM), Instituto Universitário Egas Moniz, Almada, Portugal

${ }^{5}$ Unidade de Investigação do Instituto Politécnico de Santarém, Escola Superior Agrária, Instituto Politécnico de Santarém, Santarém, Portugal

${ }^{6}$ Department of Nutrition and Dietetics, Harokopio University, Athens, Greece

${ }^{7}$ Department of Psychosomatic Medicine and Psychotherapy, Hannover Medical School, Hannover, Germany

${ }^{8}$ Department of General Practice and Primary Health Care, University of Helsinki, Helsinki, Finland

${ }^{9}$ Department of Nutrition Sciences, University of Alabama at Birmingham, Birmingham, Alabama

${ }^{10}$ Laboratório de Nutrição, Faculdade de Medicina, Universidade de Lisboa, Lisbon, Portugal

\section{Correspondence}

Inês Santos, Centro Interdisciplinar para o Estudo da Performance Humana, Faculdade de Motricidade Humana, Universidade de Lisboa, Estrada da Costa, Cruz Quebrada 1495-688, Portugal.

Email: isantos@fmh.ulisboa.pt

Funding information Foundation for Science and Technology Portugal, Grant/Award Number: PTDC/DES/72317/2006, 2008-2011

\section{Summary}

Weight loss maintenance is a major challenge for obesity treatment. Weight control registries can be useful in identifying psychological and behavioural factors that could contribute to better long-term success. The objective of this study is to describe the existing weight control registries and their participants and identify correlates of weight loss maintenance. A comprehensive search of peer-reviewed articles published until November 2018 was conducted in PubMed, Web of Science, and Scopus. Studies that reported results from weight control registries were considered. Fiftytwo articles, corresponding to five registries (the United States, Portugal, Germany, Finland, and Greece), were included. Registries differed in inclusion criteria and procedures. Of 51 identified weight loss and maintenance strategies, grouped in 14 domains of the Oxford Food and Activity Behaviors taxonomy, the following were the most frequently reported: having healthy foods available at home, regular breakfast intake, increasing vegetable consumption, decreasing sugary and fatty foods, limiting certain foods, and reducing fat in meals. Increased physical activity was the most consistent positive correlate of weight loss maintenance. To our knowledge, this is the first systematic review of information about successful weight loss maintenance obtained from weight control registries. Key common influential characteristics of success were identified, which can inform future prospective studies and weight management initiatives.

\section{KEYWORDS}

behaviours, correlates, weight loss maintenance 


\section{1 | INTRODUCTION}

Preventing weight regain after weight loss (WL) remains the biggest challenge in obesity treatment. Behavioural interventions that address diet and physical activity are moderately effective in the short term, but most individuals experience significant weight regain (returning to baseline values) in the long term. ${ }^{1}$ However, successful weight loss maintenance (WLM) is critical to uphold health benefits. ${ }^{2}$ Therefore, a deeper understanding of the factors that can facilitate long-term WLM is needed in order to provide (the high number of) individuals actively trying to lose weight ${ }^{3}$ with proven solutions/strategies for lifelong weight management.

The US National Weight Control Registry pioneered the study of successful WLM, identifying several psychological and behavioural characteristics of individuals who achieved long-term success. ${ }^{4,5}$ Subsequently, weight control registries were developed in several other countries, with the same goal of studying successful maintenance of WL (eg, previous studies ${ }^{6-9}$ ).

The process of WLM involves complex interactions among behavioural, physiological, environmental, and cognitive/psychosocial factors. ${ }^{10}$ It is well known that WLM relies on permanent adjustments between energy intake-reducing behaviours and energy expenditureincreasing behaviours. ${ }^{11}$ How that is achieved is poorly understood. Some psychological determinants such as self-efficacy (ie, for monitoring one's weight and eating behaviour), ${ }^{11-13}$ autonomous motivation, and a positive body image ${ }^{14}$ appear to impact behaviour change, but our understanding of the psychological, social, physical, and environmental determinants of WLM is incomplete. ${ }^{11,15}$ Weight control registries, where successful individuals are studied, are tools that may be helpful in better understanding the factors that impact long-term WLM, and they have not been systematically evaluated so far.

This systematic review aimed to (a) identify and describe existing weight control registries (eg, regarding inclusion/exclusion criteria, recruitment procedures, and assessments and instruments used); (b) describe the sociodemographic, cognitive, and behavioural characteristics of their participants (ie, individuals who successfully achieved long-term WLM); and (c) synthesize the sociodemographic, behavioural, and psychological correlates of WLM magnitude.

\section{2 | METHODS}

This systematic review is reported in accordance with MOOSE Guidelines (Meta-analysis of Observational Studies in Epidemiology). ${ }^{16}$ Key methodological features of this review were specified in advance and documented in a protocol (PROSPERO International Prospective Register of Systematic Reviews: registration number CRD42019129637).

\subsection{Eligibility criteria}

Studies were selected for this review if they included data obtained from existing weight control registries. Review, perspective, and commentary articles were not included, nor articles written in languages other than English and Portuguese.

\section{2 | Search strategy and study selection}

A comprehensive search of peer-reviewed articles (published up to November 2018 or ahead of print) was conducted in three electronic databases: PubMed, Web of Science, and Scopus. Searches included combinations of the following terms: "weight loss maintenance", "weight control registry", "national weight control registry", Portuguese, Greek, Finnish, and German. The full search strategy is available from the authors upon request. Additionally, manual crossreferencing of retrieved articles and hand searches of key scientific journals and the registries websites were performed.

Two authors (C.P. and I.S.) screened titles and abstracts of potentially eligible studies. Duplicate entries were removed. Relevant articles were then retrieved for a full-text review. The same two researchers independently reviewed the full text of potential studies. Discrepancies were resolved by consensus. Endnote X7 for Mac OS X was used for reference managing.

\section{3 | Quality assessment}

The methodological quality of included studies was assessed using an adapted version of the Quality Assessment Tool For Quantitative Studies developed by the Effective Public Health Practice Project $^{17}$ and recommended for use by the Cochrane Public Health Review Group. ${ }^{18}$ This tool was previously used in other systematic reviews including observational studies (eg, previous studies ${ }^{14,19}$ ). It addresses seven key domains: (a) study design, (b) selection bias, (c) withdrawals and dropouts, (d) confounders, (e) data collection, (f) data analysis, and (g) reporting. Each domain was classified as strong, moderate, or weak, and a global rating was determined. Two of four researchers (C.P., I.S., R.J., and E.V.C.) independently rated each of the seven domains and overall quality of each study. Disagreements were resolved by consensus. Interrater agreement across categories was adequate (Cohen $\kappa=.61) .{ }^{20}$

\subsection{Data extraction}

A data extraction form was developed to compile information about (a) the weight control registries that included designation, country of origin, year of implementation, sample size, recruitment procedure, period of recruitment, inclusion and exclusion criteria, assessments, and instruments used; (b) the participants-specifically, their sociodemographic characteristics (eg, sex, age, ethnicity, educational level, employment, and marital status), weight history (lifetime maximum weight and body mass index [BMl; $\mathrm{kg} \mathrm{m}^{-2}$, baseline weight and BMI, WL $[\mathrm{kg}]$ and period of WLM at registry entry, and weight stability at follow-up), and the cognitive and 
TAB LE 1 Weight control registries' and participants' characteristics

\begin{tabular}{|c|c|c|c|c|c|}
\hline \multirow[b]{2}{*}{ Designation } & $\begin{array}{l}\text { National Weight } \\
\text { Control Registry } \\
\text { (NWCR) }\end{array}$ & $\begin{array}{l}\text { Portuguese Weight } \\
\text { Control Registry } \\
\text { (PWCR) }^{6,52-54}\end{array}$ & $\begin{array}{l}\text { German Weight } \\
\text { Control Registry } \\
(\text { GWCR) }\end{array}$ & $\begin{array}{l}\text { Finnish Weight } \\
\text { Control Registry } \\
\text { (FWCR) }^{7,59-61}\end{array}$ & MedWeight $^{62-67}$ \\
\hline & United States & Portugal & Germany & Finland & Greece \\
\hline \multicolumn{6}{|c|}{ Weight control registries' characteristics } \\
\hline $\begin{array}{l}\text { Year of } \\
\text { implementation }\end{array}$ & 1993 & 2008 & 2009 & 2012 & 2012 \\
\hline \multicolumn{6}{|c|}{ Participants' sociodemographic characteristics ${ }^{a}$} \\
\hline $\begin{array}{l}\text { Maximum sample } \\
\text { size reported }\end{array}$ & $5320^{41, b}$ & $388^{53, c}$ & $494^{8}$ & $158^{7}$ & $528^{62, d}$ \\
\hline Age (y) & $47.0 \pm 12.2$ & $39.0 \pm 11.1$ & $47.6 \pm 12.7$ & $44.5 \pm 11.0$ & Regainers: 37 (29-45) \\
\hline $\begin{array}{l}\text { Ethnicity (\% } \\
\text { white) }\end{array}$ & 95.0 & - & - & - & - \\
\hline $\begin{array}{l}\text { Education (\% } \\
\text { higher) }\end{array}$ & 85.0 (college) & $\begin{array}{l}69.1 \text { (university } \\
\text { degree) }\end{array}$ & $\begin{array}{l}46.8 \text { (academic } \\
\quad \text { degree) }(n=492)\end{array}$ & 22.8 (>14 y of school) & $\begin{array}{l}16.0 \pm 3.0 y \text { of school } \\
(n=411)^{65}\end{array}$ \\
\hline \multirow[t]{2}{*}{$\begin{array}{l}\text { Employment (\% } \\
\text { employed) }\end{array}$} & \multirow[t]{2}{*}{$74.0(n=1422)^{23}$} & \multirow[t]{2}{*}{$78.7(n=198)^{6}$} & \multirow[t]{2}{*}{$76.9(n=489)$} & \multirow[t]{2}{*}{76.6} & $\begin{array}{l}\text { Maintainers: } 52 \\
\quad(n=289)\end{array}$ \\
\hline & & & & & $\begin{array}{l}\text { Regainers: } 62 \\
\qquad(\mathrm{n}=122)^{65}\end{array}$ \\
\hline \multirow{2}{*}{$\begin{array}{l}\text { Lifetime } \\
\qquad \text { maximum BMI } \\
\left(\mathrm{kg} \mathrm{m}^{-2}\right)\end{array}$} & \multirow[t]{2}{*}{$36.3 \pm 8.1(n=3683)^{4}$} & \multirow[t]{2}{*}{$33.1 \pm 6.4(n=225)$} & \multirow[t]{2}{*}{$33.2 \pm 6.5$} & \multirow[t]{2}{*}{35.9 (range 29.2-64.8) } & $\begin{array}{l}\text { Maintainers: } 33.1 \\
\quad \pm 6.9\end{array}$ \\
\hline & & & & & $\begin{array}{l}\text { Regainers: } 32.4 \pm 5.2 \\
(n=411)^{65}\end{array}$ \\
\hline $\begin{array}{l}\text { Weight at } \\
\text { baseline (kg) }\end{array}$ & $\begin{array}{l}71.5 \pm 15.9 \\
(n=3683)^{4}\end{array}$ & $74.1 \pm 13.4(n=225)$ & - & - & $\begin{array}{c}78.1 \pm 16.5 \\
(n=239)^{67}\end{array}$ \\
\hline \multirow[t]{2}{*}{$\begin{array}{l}\text { BMl at baseline } \\
\left(\mathrm{kg} \mathrm{m}^{-2}\right)\end{array}$} & \multirow[t]{2}{*}{$25.1 \pm 4.5$} & \multirow[t]{2}{*}{$26.6 \pm 4.2(n=225)$} & \multirow[t]{2}{*}{$25.7 \pm 4.2$} & \multirow[t]{2}{*}{26.1 (range 17.3-41.2) } & $\begin{array}{c}\text { Maintainers: } 25.0 \\
(22.8-28.1)\end{array}$ \\
\hline & & & & & $\begin{array}{c}\text { Regainers: } 30.1 \\
(27.6-34.3)\end{array}$ \\
\hline \multirow[t]{2}{*}{$\begin{array}{l}\text { Weight loss at } \\
\text { baseline }(\mathrm{kg})\end{array}$} & \multirow[t]{2}{*}{$\begin{array}{l}32.3 \pm 16.7 \\
\quad(n=3683)^{4}\end{array}$} & \multirow[t]{2}{*}{$18.3 \pm 12.5(n=225)$} & - & 32.4 (range 9-81) & $\begin{array}{l}\text { Maintainers: } 25.6 \\
\quad \pm 15.8\end{array}$ \\
\hline & & & & & $\begin{array}{l}\text { Regainers: } 14.5 \pm 4.5 \\
\quad(\mathrm{n}=226)^{63}\end{array}$ \\
\hline
\end{tabular}


TABLE 1 (Continued)

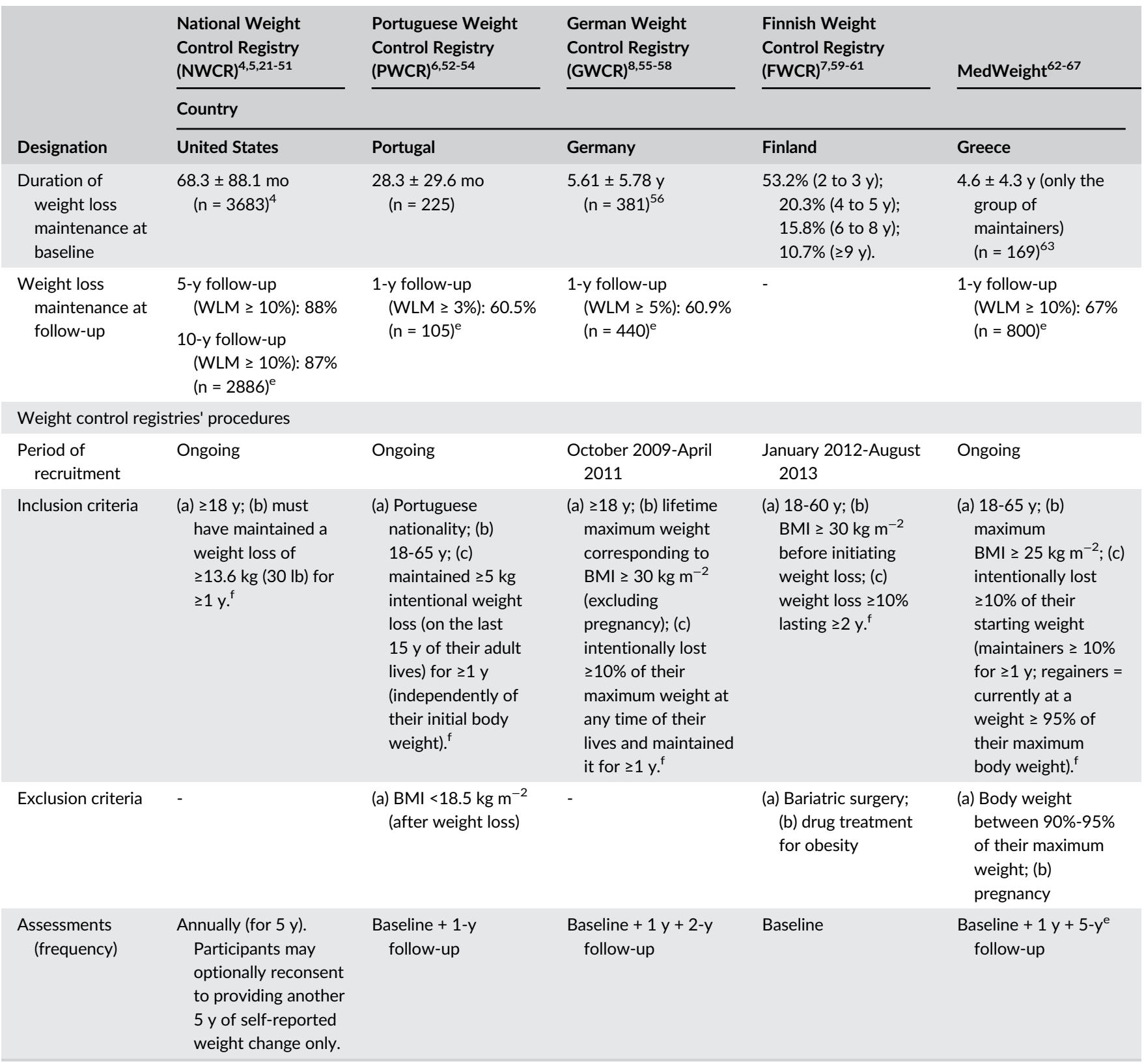

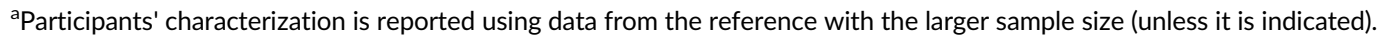

${ }^{\mathrm{b}}$ Maximum sample size known is over 10000 participants.

'Maximum sample size known is 402 participants.

${ }^{\mathrm{d}}$ Maximum sample size known is 756 participants.

${ }^{\mathrm{e}}$ This information was provided by the principal investigator of the weight control registry.

${ }^{f}$ Weight and weight loss are self-reported by the participants.

behavioural weight control strategies used; and (c) the sociodemographic, behavioural, and psychological correlates of the magnitude of WLM. Two of four researchers (C.P., I.S., R.J., and E.V.C.) independently extracted the data.

\section{5 | Data synthesis}

Registries' characteristics and participants' sociodemographic characteristics, as well as the cognitive and behavioural strategies they used for weight management, were qualitatively synthetized and presented in tabular form (Tables 1 and 2, respectively). When the same characteristic or strategy was reported in several articles from the same registry, the one with a larger sample was used. The prevalence of each strategy was estimated by combining data derived from the largest sample size reported in each registry. Weight management strategies were independently classified within the domains of the Oxford Food and Activity Behaviors (OxFAB) taxonomy ${ }^{68}$ by two of four researchers (C.P., I.S., R.J., and E.V.C.). Discrepancies were resolved by consensus. This taxonomy was 
chosen because it is a comprehensive tool to systematically describe the cognitive and behavioural strategies used by individuals attempting to manage their weight. ${ }^{68}$ Only the domains including at least one strategy were shown. One additional domain was included- dietary choices-as some of the reported strategies did not fit within any existing domain. Some strategies seemed to fit in more than one domain; nevertheless, by agreement, we have selected the most appropriate one.

TAB LE 2 Cognitive and behavioural weight management strategies used by participants of weight control registries

\begin{tabular}{|c|c|c|c|c|c|c|c|c|}
\hline \multirow[b]{2}{*}{$\begin{array}{l}\text { Domains } \\
\text { Strategies }\end{array}$} & \multicolumn{4}{|c|}{ Weight Loss Strategies } & \multicolumn{4}{|c|}{ Weight Loss Maintenance Strategies } \\
\hline & $\begin{array}{l}\text { Number of } \\
\text { Studies }\end{array}$ & $\mathbf{n}$ & $\begin{array}{l}\text { Prevalence } \\
\text { (\%) }\end{array}$ & References & $\begin{array}{l}\text { Number of } \\
\text { Studies }\end{array}$ & $\mathbf{n}$ & $\begin{array}{l}\text { Prevalence } \\
\text { (\%) }\end{array}$ & References \\
\hline \multicolumn{9}{|l|}{ Dietary choices } \\
\hline Increase vegetable consumption & 2 & 546 & 86.6 & 53,61 & 1 & 388 & 88.8 & 53 \\
\hline Regular breakfast intake ${ }^{a, 24}$ & 1 & 388 & 89.8 & 53 & 1 & 388 & 96.6 & 53 \\
\hline Regular soup intake & 1 & 388 & 50.5 & 53 & 1 & 388 & 50.3 & 53 \\
\hline $\begin{array}{l}\text { Increase protein-rich foods } \\
\text { consumption (eg, eggs, fish, and } \\
\text { meat) }\end{array}$ & 1 & 388 & 36.0 & 53 & 1 & 388 & 43.5 & 53 \\
\hline Increase fibre-rich foods consumption & 1 & 388 & 77.0 & 53 & 1 & 388 & 83.6 & 53 \\
\hline \multicolumn{9}{|l|}{ Energy compensation ${ }^{b}$} \\
\hline Physical activity/exercise ${ }^{c}$ & 3 & 3683 & 88.6 & $4,5,38$ & 1 & 388 & 67.5 & 53 \\
\hline Using stairs rather than elevators & 1 & 388 & 45.7 & 53 & 0 & - & - & - \\
\hline $\begin{array}{l}\text { Walk instead of driving/taking public } \\
\text { transportation }^{a, 53}\end{array}$ & 1 & 388 & 38.0 & 53 & 0 & - & - & - \\
\hline Parking away from destination & 1 & 388 & 20.4 & 53 & 0 & - & - & - \\
\hline \multicolumn{9}{|l|}{ Goal setting } \\
\hline $\begin{array}{l}\text { Establishing specific goals (eg, } \\
\text { regarding weight loss and physical } \\
\text { activity) }\end{array}$ & 1 & 388 & 60.6 & 53 & 1 & 388 & 49.1 & 53 \\
\hline \multicolumn{9}{|l|}{ Imitation (modelling) } \\
\hline $\begin{array}{l}\text { Followed a diet programme (obtained } \\
\text { from a fad book, magazine or } \\
\text { another person) }^{d}\end{array}$ & 2 & 2964 & 23.6 & 40,63 & 0 & - & - & - \\
\hline \multicolumn{9}{|l|}{ Information seeking } \\
\hline $\begin{array}{l}\text { Conscious food selection (eg, read } \\
\text { labels) }\end{array}$ & 1 & 388 & 79.8 & 53 & 1 & 388 & 72.7 & 53 \\
\hline Seek weight loss information online & 1 & 158 & 4.4 & 59 & 0 & - & - & - \\
\hline Diet/exercise books/magazines & 0 & - & - & - & 1 & 2228 & 72.4 & 5 \\
\hline \multicolumn{9}{|l|}{ Motivation } \\
\hline $\begin{array}{l}\text { Kept picture of self in a prominent } \\
\text { place }\end{array}$ & 0 & - & - & - & 1 & 931 & 23.6 & 31 \\
\hline Lost weight by self ${ }^{d}$ & 3 & 356 & 68.8 & $52,59,63$ & 0 & - & - & - \\
\hline \multicolumn{9}{|l|}{ Planning content } \\
\hline $\begin{array}{l}\text { Healthy foods available at home (eg, } \\
\text { fruits and vegetables) }{ }^{a, 53, e}\end{array}$ & 1 & 388 & 92.7 & 53 & 2 & 1319 & 89.7 & 31,53 \\
\hline Few high-fat foods available at home & 0 & - & - & - & 1 & 931 & 83.2 & 31 \\
\hline \multicolumn{9}{|l|}{ Regulation-restrictions } \\
\hline Follow a special/fad diet ${ }^{d}$ & 3 & 1664 & 16.2 & $21,38,63$ & 1 & 893 & 17.0 & 26 \\
\hline Reduce portion sizes ${ }^{\mathrm{a}, 53}$ & 2 & 546 & 72.5 & 53,61 & 1 & 388 & 64.6 & 53 \\
\hline Decrease alcohol intake & 1 & 158 & 34.8 & 61 & 0 & - & - & - \\
\hline Decrease intake of soft drinks & 1 & 158 & 53.8 & 61 & 0 & - & - & - \\
\hline
\end{tabular}


TABLE 2 (Continued)

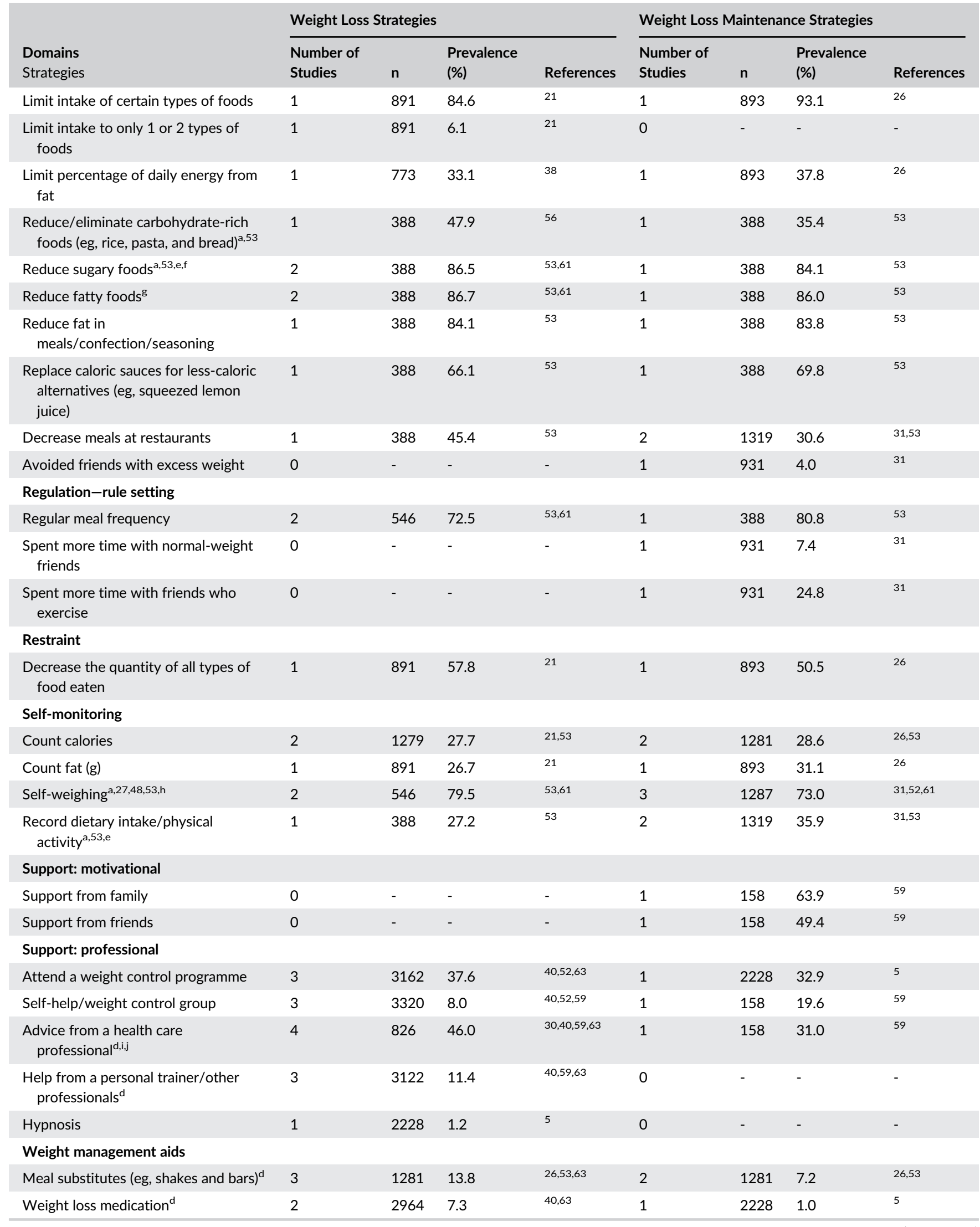


TABLE 2 (Continued)

\begin{tabular}{|c|c|c|c|c|c|c|c|c|}
\hline \multirow[b]{2}{*}{$\begin{array}{l}\text { Domains } \\
\text { Strategies }\end{array}$} & \multicolumn{4}{|c|}{ Weight Loss Strategies } & \multicolumn{4}{|c|}{ Weight Loss Maintenance Strategies } \\
\hline & $\begin{array}{l}\text { Number of } \\
\text { Studies }\end{array}$ & $\mathbf{n}$ & $\begin{array}{l}\text { Prevalence } \\
\text { (\%) }\end{array}$ & References & $\begin{array}{l}\text { Number of } \\
\text { Studies }\end{array}$ & $\mathbf{n}$ & $\begin{array}{l}\text { Prevalence } \\
\text { (\%) }\end{array}$ & References \\
\hline Surgery ${ }^{d}$ & 2 & 2228 & 3.7 & 5,63 & 0 & - & - & - \\
\hline Weight loss supplements ${ }^{k, 53}$ & 1 & 388 & 15.1 & 53 & 1 & 388 & 11.5 & 53 \\
\hline
\end{tabular}

Note. The prevalence of each strategy is reported using combined data derived from the largest sample size reported in each registry.

${ }^{a}$ This strategy was found to be positively associated with weight control (loss, maintenance, or both) in terms of magnitude (reference of the article/s).

${ }^{b}$ Physical activity was considered in the Energy Compensation domain because this strategy is commonly used to compensate energy intake as a way to control weight.

${ }^{\mathrm{c}}$ Studies of Ogden et $\mathrm{al}^{5}$ and Klem et al ${ }^{38}$ were not accounted for sample size or prevalence rates because of assessment differences (separate nonmutually exclusive values for exercising at home, with friends, or with a structured group).

${ }^{\mathrm{d} S t u d y}$ of Karfopoulou et $\mathrm{al}^{63}$ was not accounted for sample size or prevalence rates because the exact frequencies were not reported.

${ }^{\mathrm{e}}$ Association observed only in women.

${ }^{f}$ Study of Soini et al ${ }^{61}$ was not accounted for sample size or prevalence rates because of assessment differences (separate nonmutually exclusive values for candies, sweet pastries, and fast carbohydrates).

${ }^{\mathrm{g}}$ Study of Soini et al ${ }^{61}$ was not accounted for sample size or prevalence rates because of assessment differences (separate nonmutually exclusive values for fast food, high-fat cold cuts/sausages, and high-fat cheeses).

${ }^{\mathrm{h}}$ Study of Soini et al ${ }^{61}$ reports self-weighing as monitoring weight at least once a week.

'Assisted weight loss was interpreted as receiving advice from a health care professional.

${ }^{\mathrm{j}}$ Study of LaRose et al ${ }^{40}$ was not accounted for sample size or prevalence rates because of assessment differences (separate nonmutually exclusive values for advice from different health care professionals).

${ }^{\mathrm{k}}$ This strategy was found to be negatively associated with weight control (loss, maintenance, or both) in terms of magnitude (reference of the article/s).

The sociodemographic, behavioural, and psychological correlates of the magnitude of WLM (ie, weight change expressed in kilograms or percentage) were also summarized in tabular form, according to (a) the number of studies that assessed each correlate and (b) the association effect found, namely, "no association", "positive association", or "negative association" (Table 3). All associations identified through Pearson and Spearman correlations were considered. In some specific cases, linear and multiple regressions, odds ratio/relative risk, and $\chi^{2}$ (with post-hoc tests) were also considered. Since different studies from the same registry reported different statistical analyses (with different sample sizes and in different assessment moments) using the same correlate, all the tested associations were included. Because of the limited number of studies reporting each strategy and correlate, we did not conduct meta-analyses.

\section{3 | RESULTS}

The literature search yielded a total of 2992 records. Fifteen articles, identified through manual searches and cross-referencing, were added, leading to a total of 3007 potential articles (Figure 1). After removal of duplicates ( $n=1324$ ), 1683 articles were assessed for eligibility. Of these, 1524 were excluded based on title/abstract screening, leaving 159 eligible for full-text screening. Fifty-two articles (published between 1997 and 2018) met eligibility criteria and were included in the present review.

\section{1 | Methodological appraisal}

The overall methodological quality of the 52 included studies was rated as moderate and weak in 48 and 4 studies, respectively. All study designs were rated as moderate since they were all observational studies. Similarly, all were rated as weak for selection bias, since registry participants are volunteers and therefore not likely to be representative of the target population. Thirteen studies scored moderate in terms of withdrawals and dropouts. The other 39 were not rated as they had a cross-sectional design. Concerning adjustment for confounders, two studies were rated as weak and 50 were rated as strong. Two studies scored weak on data collection, as they did not provide information on measures of validity or reliability; four were classified as moderate and 46 as strong. Most studies $(k=51)$ were classified as strong regarding the use of appropriate statistical analyses. One study was rated as weak because it did not report the statistical analyses used. Fifty studies were rated as strong and two as moderate for reporting. Table S1 provides a detailed classification of each domain and the overall methodological quality of each study.

\section{2 | Weight control registries' and participants' characteristics}

Characteristics of the five weight control registries found and the sociodemographic characteristics of their participants are summarized in Table 1 and in Table S2. The first registry was 
TAB LE 3 Association of sociodemographic, behavioural, and psychological characteristics with the magnitude of weight loss maintenance

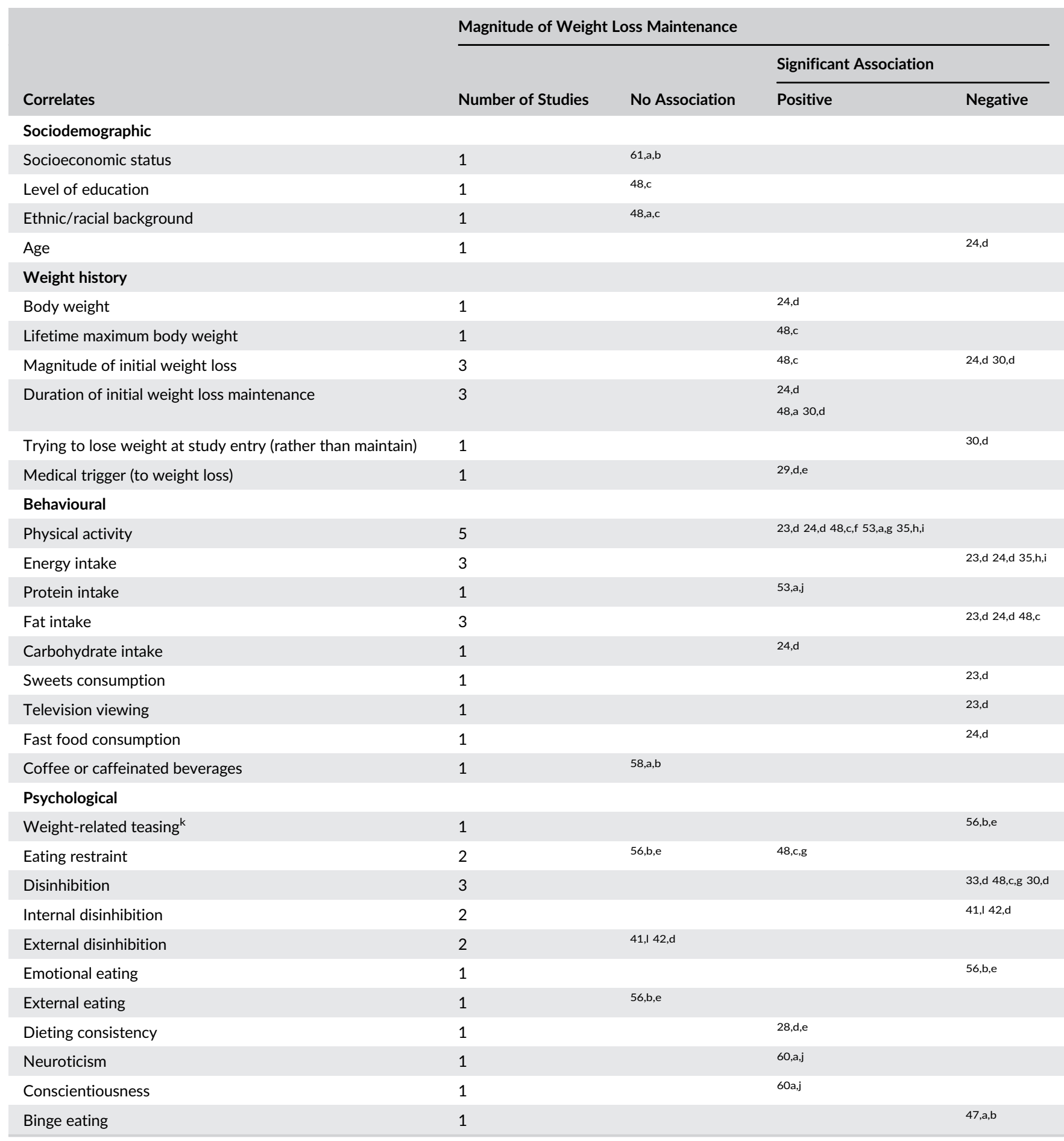

Note. Having a healthy eating pattern, ${ }^{64, a, m, n}$ sleep quality, ${ }^{62, a, m}$ and internal orientation (locus of control) ${ }^{67, a}$ were positively associated with weight loss maintenance status. Total support ${ }^{65, a}$ was negatively associated with weight loss maintenance status. Total sabotage ${ }^{65, a}$ was not associated with weight loss maintenance status.

${ }^{a}$ Weight loss maintenance (WLM) at baseline.

${ }^{b}$ WLM expressed as a difference in BMI.

'WLM over 10-y follow-up.

${ }^{d}$ WLM at 1-y follow-up.

eWLM at 2-y follow-up.

fLeisure-time physical activity.

${ }^{\mathrm{g}}$ Moderate-plus-vigorous physical activity.

hWLM at 3-y follow-up. 
'Baseline levels were not predictive of weight regain. Decreased physical activity levels or increased energy intake over time was associated with 3-y weight regain.

${ }^{\mathrm{j} A s s o c i a t i o n ~ o b s e r v e d ~ o n l y ~ i n ~ w o m e n . ~}$

${ }^{\mathrm{k}}$ Retrospective weight-related teasing during childhood and adolescence.

'WLM over 5-y follow-up.

mAssociation observed only in men.

"Healthy eating pattern = higher consumption of unprocessed cereal, fruit, vegetables, eggs, olive oil, beverages (such as coffee and tea), low-fat dairy, and low-fat cheese; and lower consumption of processed cereal, sweets, spreads/sauces, high-fat cheese, and junk food.

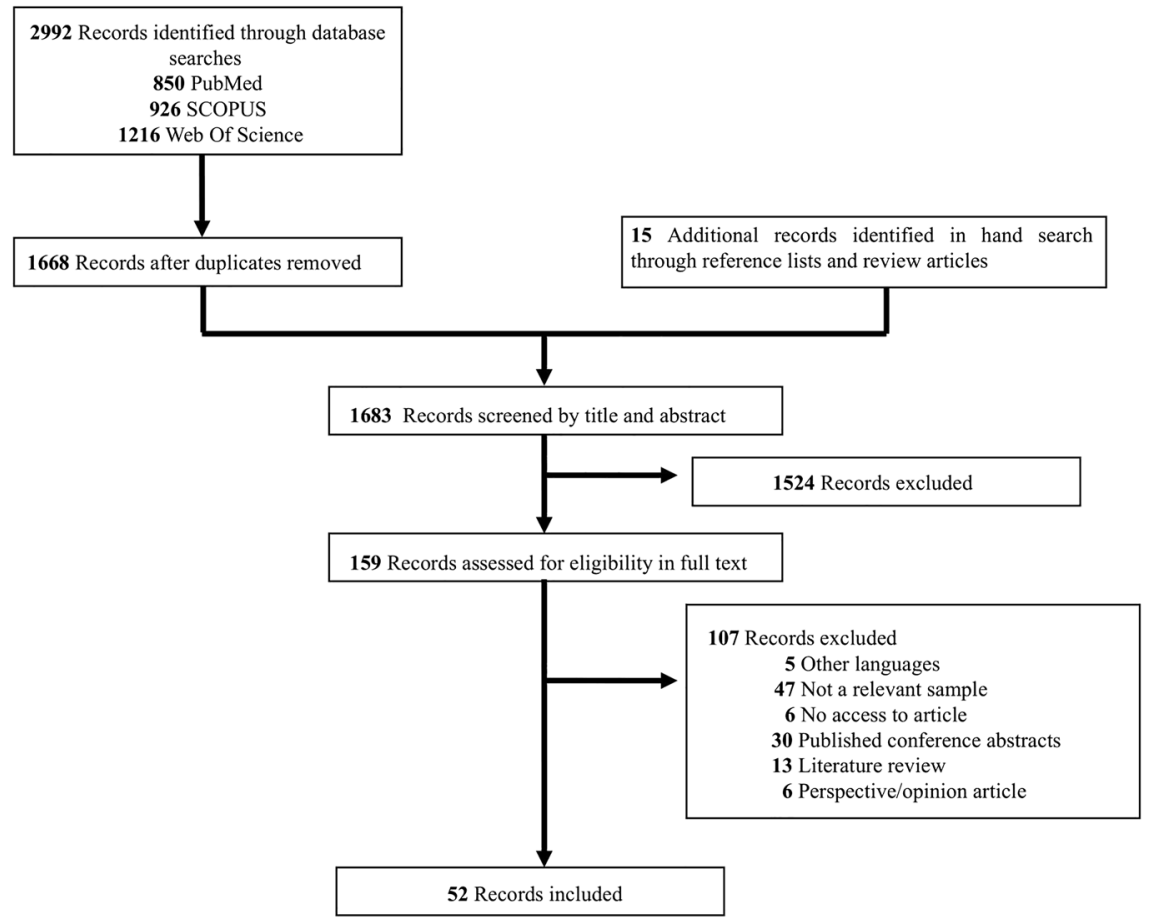

FIGURE 1 Flow diagram of studies

implemented in the United States in 1993, while the others were implemented between 2008 and 2012 in four European countries. Recruitment procedures, use of incentives, and eligibility slightly differed between registries. Across the five registries, age (18 years and older) was a common requisite for entering. The required WL for entry, however, differed between registries. Germany, Finland, and Greece requested an initial WL of at least $10 \%$, whereas Portugal and the United States established a WL of at least 5 and $13.6 \mathrm{~kg}(30 \mathrm{lb})$, respectively. Some registries (Germany, Finland, and Greece) also required having excess weight prior to $W L$ as an entry criterion. Four registries required maintaining the weight lost for at least 1 year, but the Finnish registry required at least 2 years of WLM. The MedWeight study (Greece) distinguishes maintainers from regainers at study entry, ie, people who have lost weight but regained some part of it (weight at study entry $\geq 95 \%$ of their maximum body weight). The frequency and methods of assessment also differed between registries. The Finnish registry has a single assessment moment, while the others have at least two assessment moments. The US registry assesses participants annually for 10 years. All registries collect information on sociodemographics, lifestyle habits, personal and familiar medical history, and psychometrics. They all include some kind of dietary intake and structured physical activity measurement. Anthropometric data are generally self-reported, except in the Portuguese registry where individuals are objectively measured (weight, height, and waist circumference) and in the US registry where subsets of participants were studied in-person for specific studies.

The US registry is the largest, reporting over 10000 participants. The four European registries have several hundred participants each. From weight history assessments, the registry participants had maximum BMls between 32.4 and $36.3 \mathrm{~kg} \mathrm{~m}^{-2}$ and BMls between 25.1 and $30 \mathrm{~kg} \mathrm{~m}^{-2}$ at registry entry. Participants in all registries had variable average WLs (14.5-32.4 kg) and variable time periods over which the WL was maintained (28-68 months). WLM at follow-up (considering maintenance of at least $3 \%$ to $10 \% \mathrm{WL}$, depending on the criteria used by each registry) was observed in $60.5 \%$ to $88 \%$ of the participants. 


\section{3 | Cognitive and behavioural weight management strategies}

Thirteen studies across four countries reported strategies used by participants for WL and WLM (Table 2). From these studies, 51 strategies, grouped in 14 domains of the OxFAB taxonomy, were identified.

The most frequently reported strategies ( $\geq 80 \%$ ) for $W L$ were classified in the following domains: planning content (having healthy foods available at home), dietary choices (regular breakfast intake and increasing vegetable consumption), energy compensation (engaging in physical activity/exercise), and regulation-restrictions (reducing the consumption of sugary and fatty foods, limiting intake of certain types of foods, and reducing fat in meals) domains. The least frequently reported strategies $(\leq 20 \%)$ were in the following domains: support-professional (hypnosis, self-help/help from a weight control group, and help from a personal trainer or other professional), weight management aids (surgery, taking WL medication, using meal substitutes, and consuming WL supplements), information seeking (seeking WL information online), and regulation-restrictions (limiting intake to only one or two types of food and following a special or fad diet).

For WLM, the majority of participants ( $>80 \%$ ) relied on regular breakfast intake, increasing the consumption of vegetables and fibrerich foods (dietary choices domain); limiting intake of certain types of foods, reducing the consumption of fatty and sugary foods, and reducing fat in meals (regulation-restrictions domain); having healthy foods and few high-fat foods available at home (planning content domain); and having a regular meal frequency (regulation-rule setting domain). Less than $20 \%$ of participants reported taking WL medication, using meal substitutes, and consuming WL supplements (weight management aids domain); avoiding friends with excess weight and following a special or fad diet (regulation-restrictions domain); spending more time with normal-weight friends (regulation-rule setting domain); and having help from a weight control group (supportprofessional domain).

\subsection{Correlates of the magnitude of WLM}

Table 3 shows a data analytic synthesis of the 30 sociodemographic, behavioural, and psychological correlates of the magnitude of WLM tested in 16 of 52 studies. Physical activity was the most frequently studied correlate $(k=5)$ with all of the studies reporting a positive association with the magnitude of WLM. Energy intake and fat intake were tested as correlates of the magnitude of WLM in three studies each and were found to be negatively associated in all of the studies. The amount of sustained WL prior to study entry was also tested as a correlate of the magnitude of WLM at follow-up ( $k=3$ ): Only one study showed a positive association. The duration of WLM before entering the registry was tested in three studies, with all showing positive associations with the magnitude of WLM. General eating disinhibition $(k=3)$ and internal and external disinhibition $(k=2)$ were also tested as correlates of the magnitude of WLM, with general and internal eating disinhibition being identified as consistent negative correlates. Several variables were identified as positive correlates of the magnitude of WLM, although in less than three studies: body weight, lifetime maximum body weight, medical trigger, protein and carbohydrate intake, dieting consistency, neuroticism, and conscientiousness (Table 3); and regular breakfast intake, increasing protein-rich foods' consumption, walking instead of driving/taking public transportation, establishing specific goals, reducing portions size, reducing/eliminating carbohydrate-rich foods, and self-weighing (Table 2). The following strategies were associated with the magnitude of WLM only in women: having healthy foods available at home, reducing sugary foods, and recording dietary intake/physical activity (Table 2).

\section{4 | DISCUSSION}

This systematic review identified sociodemographic, cognitive, and behavioural characteristics of successful WL maintainers from five country-specific weight control registries, as well as correlates of the magnitude of WLM. To the best of our knowledge, this is the first review providing a comprehensive comparison of the existing weight control registries and their participants, allowing the identification of common key influential characteristics. Information from weight control registries is useful in guiding further prospective research and may be useful in helping direct future public health and weight management interventions and policies.

Fifty-two studies from five weight control registries (the United States, Portugal, Germany, Finland, and Greece) were included. Although having a common goal of studying successful maintenance of $W L$ in their populations, each registry has unique recruitment strategies, enrolment criteria, and assessments. Across participants from four weight control registries, 51 different personal strategies were reported for WL and WLM. The most frequently reported were having healthy foods available at home, having regular breakfast intake, increasing vegetables' consumption, reducing the consumption of sugary and fatty foods, and reducing fat in meals (within the planning content, dietary choices, and regulationrestrictions domains of the OxFAB taxonomy). Finally, 30 different sociodemographic, behavioural, and psychological correlates of the magnitude of WLM were identified; the most frequently studied was physical activity, which showed a consistent positive association.

These weight control registries, while not providing a quantitative measure of success, have demonstrated that some people are succeeding in long-term WL. This information can provide motivation and hope to those struggling to achieve long-term weight reductions. All registries have set a realistic, clinically significant minimum amount of WL for eligibility ${ }^{2}$ (for example, in Portugal, a 5-kg WL represents more than $5 \% \mathrm{WL}$ for most individuals with excess weight), ${ }^{69,70}$ suggesting that participants improved their lifestyle and health. However, participants have used a variety of different (and, to some 
extent, individualized) behavioural strategies to achieve $\mathrm{WL}$ and WLM. These results suggest that there is no "one size fits all" approach for WL and WLM. Instead, participants seem to rely on different sets or combinations of cognitive and behavioural strategies, with some uncommon behaviours being very important for some participants.

In line with the most recent obesity treatment guidelines, ${ }^{2,71,72}$ the most frequently reported strategies encompassed reductions in energy intake and increases in energy expenditure (through physical activity/exercise). In fact, physical activity, total energy intake, and also fat intake were the most consistent behavioural correlates of the magnitude of WLM, which is corroborated by a recent systematic review on determinants of WLM. ${ }^{11}$ These results suggest, in line with previous guidelines (eg, Donnelly et $\mathrm{al}^{73}$ ), that there is likely a doseresponse effect, with greater WLs being achieved and maintained with greater doses of physical activity and lower energy and fat intake (despite the cross-sectional data analysis).

Other popular strategies among WL maintainers related to planning behaviour (having healthy foods available at home) and improving the quality of the diet by making healthier choices (eg, increasing vegetable consumption), which are also aligned with evidence-based guidelines for weight management (eg, Jensen et $\mathrm{al}^{2}$ ). While the literature is mixed with regard to the importance of eating breakfast for obesity, ${ }^{74-77}$ it was positively associated with the magnitude of WLM. The role of protein in obesity treatment is also controversial. ${ }^{11,78,79}$ However, in this review, the consumption of protein-rich foods and protein intake was also found to be positively associated with the magnitude of WLM. Consistent with prior research, ${ }^{11,80,81}$ results from weight control registries find reducing portion sizes, as a means of cutting calories, self-monitoring/selfweighing (which inform on the individual's progress towards his/her goal, increases awareness and perceived control over one's life), and specific goal setting for eating and physical activity to be positively related with the magnitude of WLM. These strategies are recommended by weight management guidelines ${ }^{72}$ and seem to act synergistically, given that when individuals monitor their progression towards their goal, they can adjust their behavioural efforts (if/when needed) and more easily attain their goals. Eating and physical activity goals should be, however, realistic and individualized, ${ }^{2}$ to prevent individuals from abandoning the weight management process.

Importantly, few participants reported using weight management aids (meal substitutes, WL pills, and supplements), and, in fact, taking WL supplements was shown to be negatively associated with weight control in one of the included studies. Other studies found limited or no evidence on the effectiveness of meal substitutes or WL supplements on WLM and even reported some potential health risks. $^{13,82,83}$

It is noteworthy that the most frequent strategies for WL were often also used for WLM. It remains unclear whether maintaining WL involves primarily a continuation of the behaviours initially adopted, $^{84}$ as the present results suggest, or whether it requires a behavioural set different from that needed to achieve initial WL. ${ }^{85}$
It is certainly possible that many of these successful maintainers still wished to lose additional weight and therefore revisited most of the strategies they adopted in the first place. Nevertheless, most of these strategies are aligned with important theoretical assumptions of behaviour change maintenance involving more internal forms of motivation, active self-regulation, habitual cue driven responses, and boundary conditions including resources and environmental factors. $^{86}$

Other notable correlates of the magnitude of WLM were identified in these registries. Consistent with other research, ${ }^{87}$ the duration of WLM at study entry was consistently and positively associated with the magnitude of WLM. This could suggest that maintenance becomes easier over time, perhaps because the newly adopted weight control behaviours become habits (automatic), demanding less conscious effort. ${ }^{86}$ Medical-triggered WL also seems to be particularly well maintained, perhaps because individuals perceive that their prior weight was the cause of the medical crisis. ${ }^{88}$ Additionally, eating in response to emotional cues seems to be consistently negatively associated with the magnitude of WLM, corroborating other studies. ${ }^{11,89}$ This behavioural trait is probably related with overeating and binge eating episodes, ${ }^{90}$ which was also found to be negatively correlated with WLM in this review. Some psychological traits, such as conscientiousness, were found to be positively associated with WLM only in women. Conscientiousness (characterized by self-control) has been found in previous studies to facilitate the adoption/maintenance of healthier behaviours over time and to lead to greater WL. ${ }^{91}$ The cultural and sex specificities underlying the relationship between weight and personality ${ }^{92,93}$ may explain results in this and in other studies. $^{93,94}$

\section{1 | Strengths and limitations}

The main strength of this systematic review is the characterization of all existing weight control registries worldwide (with published results) and, therefore, of nationally recruited samples of successful WL maintainers from different regions. Although sample sizes are considerably large, their nature (volunteers) precludes the generalization of these results to the population under scrutiny-nationwide successful WL maintainers. Recruiting individuals through web-based platforms allows the recruitment of more heterogeneous samples (eg, individuals from different counties/regions). However, it also limits participation to individuals with certain levels of digital literacy, potentially narrowing the sample characteristics. Additionally, this type of study is subject to selection bias towards more motivated individuals.

Although important characteristics, strategies, and correlates were identified (through valid and reliable instruments), discrepancies across registries, particularly regarding enrolment criteria and assessments, represent an important limitation when establishing crosscomparisons. Research in different countries and other cultural settings, with standardized methodologies and tools, would add to the generalizability by increasing accuracy and comparability. 
The self-reported nature of most data (including for registry eligibility) can lead to response bias associated with recall difficulties, social desirability, and underestimations or overestimations. ${ }^{95,96} \mathrm{Nev}$ ertheless, since there is no intervention with the participants, and most registries do not offer financial incentives or other major benefits from entering, we assume there is little reason for participants to misreport information, at least their weight history. Additionally, some studies show that self-reported data, such as weight and height, strongly correlate with objectively measured data. ${ }^{97}$

Finally, the observational nature of the registries and the crosssectional design of most studies, even though with a retrospective or prospective nature, prevents drawing firm conclusions about the causal direction of the associations between correlates and the magnitude of WLM. The possibility of reverse causality cannot be excluded, and therefore, results should only be interpreted as suggestive and supportive.

\section{2 | New project: The International Weight Control Registry}

It is clear that many factors can affect WL and WLM. It is also clear that differences among country-specific registries sometimes make it difficult to draw general conclusions. Recognizing these limitations, researchers at several universities in the United States, Europe, and Australia have recently combined forces to create the International Weight Control Registry (IWCR). By bringing together researchers from different parts of the world and with expertise in different areas, it may be possible to extend the scope of understanding of factors involved in WL and WLM. The IWCR consists of a database, accessible online, where qualified individuals can complete a comprehensive series of questionnaires about their weight management and be followed up over time. These questionnaires currently cover a broad range of variables from basic demographics, weight history, eating and physical activity behaviours, executive function, stress reactivity, and identity to environmental/contextual circumstance and more. Additional measures can be added over time. The IWCR aims to assess between-country differences and similarities in how people succeed in long-term WL. It also aims to identify how cultural, social, political, and environmental factors in different populations within different countries may impact weight maintenance success. This registry seeks to understand both what people did to become successful and how they were able to make and sustain these behavioural changes in the environment in which they live in. More information about this registry will be available soon to the scientific community, and academic centres throughout the world will have opportunities to become collaborating centres in this project.

\section{3 | Conclusions and implications}

This systematic review describes five country-specific weight control registries across the world and identifies key sociodemographic, cognitive, and behavioural characteristics of successful WL maintainers. Additionally, it reports on important correlates of the magnitude of WLM, providing insight into the public's response to the (excess) weight problem and suggesting evidence-based clues for future public health and obesity prevention and treatment initiatives.

In order to capture a better picture of real-world WL maintainers, more countries, with different sociocultural, physical, and policy milieus, should consider joining the IWCR or developing their own weight control registries, preferentially with standardized tools and methodologies to increase accuracy and comparability between them. Additional determinants influencing WLM through their effect on behaviour (eg, social, physical, and macroenvironmental) should be explored in these registries. This will help bridge the monitoring of successful WLM in the adult population, thus informing and advancing future clinical and research practice.

\section{ACKNOWLEDGEMENTS}

This study was funded by the Foundation for Science and Technology Portugal (PTDC/DES/72317/2006, 2008-2011).

\section{ORCID}

Catarina Paixão (DD https://orcid.org/0000-0002-0531-2412

Carlos M. Dias (1D) https://orcid.org/0000-0002-0206-5874

Rui Jorge (iD https://orcid.org/0000-0002-5261-2688

Eliana V. Carraça (iD https://orcid.org/0000-0002-5789-811X

Mary Yannakoulia (D) https://orcid.org/0000-0003-2171-7337

Martina de Zwaan (D) https://orcid.org/0000-0002-7918-6957

Sirpa Soini (iD) https://orcid.org/0000-0001-6190-1177

James O. Hill (D) https://orcid.org/0000-0003-4690-2264

Pedro J. Teixeira (D) https://orcid.org/0000-0001-7202-0527

Inês Santos (D) https://orcid.org/0000-0002-1638-8551

\section{REFERENCES}

1. Nordmo M, Danielsen YS, Nordmo M. The challenge of keeping it off, a descriptive systematic review of high-quality, follow-up studies of obesity treatments. Obes Rev. 2020;21(1):e12949.

2. Jensen MD, Ryan DH, Apovian CM, et al. 2013 AHA/ACC/TOS guideline for the management of overweight and obesity in adults: A report of the American College of Cardiology/American Heart Association Task Force on Practice Guidelines and The Obesity Society. Circulation. 2014;129(25 Suppl 2):S102-S138.

3. Santos I, Sniehotta FF, Marques MM, Carraca EV, Teixeira PJ. Prevalence of personal weight control attempts in adults: a systematic review and meta-analysis. Obes Rev. 2017;18(1):32-50.

4. Catenacci VA, Ogden LG, Stuht J, et al. Physical activity patterns in the National Weight Control Registry. Obesity (Silver Spring). 2008;16 (1):153-161.

5. Ogden LG, Stroebele N, Wyatt HR, et al. Cluster analysis of the national weight control registry to identify distinct subgroups maintaining successful weight loss. Obesity (Silver Spring). 2012;20 (10):2039-2047.

6. Vieira PN, Teixeira P, Sardinha LB, et al. Success in maintaining weight loss in Portugal: the Portuguese Weight Control Registry. Cien Saude Colet. 2014;19(1):83-92. 
7. Soini S, Mustajoki P, Eriksson JG. Lifestyle-related factors associated with successful weight loss. Ann Med. 2015;47(2):88-93.

8. Feller S, Muller A, Mayr A, Engeli S, Hilbert A, de Zwaan M. What distinguishes weight loss maintainers of the German Weight Control Registry from the general population? Obesity (Silver Spring). 2015;23 (5):1112-1118

9. Karfopoulou E, Mouliou K, Koutras Y, Yannakoulia M. Behaviours associated with weight loss maintenance and regaining in a Mediterranean population sample. A qualitative study. Clin Obes. 2013;3(5): 141-149.

10. MacLean PS, Wing RR, Davidson T, et al. NIH working group report: innovative research to improve maintenance of weight loss. Obesity (Silver Spring). 2015;23(1):7-15.

11. Varkevisser RDM, van Stralen MM, Kroeze W, Ket JCF Steenhuis IHM. Determinants of weight loss maintenance: a systematic review. Obes Rev. 2019;20(2):171-211.

12. Hartmann-Boyce J, Aveyard P, Piernas C, et al. Cognitive and behavioural strategies for weight management in overweight adults: results from the Oxford Food and Activity Behaviours (OxFAB) cohort study. PLoS One. 2018;13(8):e0202072.

13. Dombrowski SU, Knittle K, Avenell A, Araujo-Soares V, Sniehotta FF. Long term maintenance of weight loss with non-surgical interventions in obese adults: systematic review and meta-analyses of randomised controlled trials. BMJ. 2014;348:g2646.

14. Teixeira PJ, Carraca EV, Marques MM, et al. Successful behavior change in obesity interventions in adults: a systematic review of selfregulation mediators. BMC Med. 2015;13(1):84-99.

15. Caldwell AE, Masters KS, Peters JC, et al. Harnessing centred identity transformation to reduce executive function burden for maintenance of health behaviour change: the Maintain IT model. Health Psychol Rev. 2018;12(3):231-253.

16. Stroup DF, Berlin JA, Morton SC, et al. Meta-analysis of observational studies in epidemiology: a proposal for reporting. Meta-analysis Of Observational Studies in Epidemiology (MOOSE) group. JAMA. 2000; 283(15):2008-2012.

17. Thomas BH, Ciliska D, Dobbins M, Micucci S. A process for systematically reviewing the literature: providing the research evidence for public health nursing interventions. Worldviews Evid Based Nurs. 2004;1(3):176-184.

18. Higgins JP, Altman DG, Gotzsche PC, et al. The Cochrane Collaboration's tool for assessing risk of bias in randomised trials. BMJ. 2011; 343:d5928.

19. Mackenbach JD, Rutter $\mathrm{H}$, Compernolle $\mathrm{S}$, et al. Obesogenic environments: a systematic review of the association between the physical environment and adult weight status, the SPOTLIGHT project. BMC Public Health. 2014;14(1):233-247.

20. McHugh ML. Interrater reliability: the kappa statistic. Biochem Med (Zagreb). 2012;22(3):276-282.

21. Phelan S, Wyatt H, Nassery S, et al. Three-year weight change in successful weight losers who lost weight on a low-carbohydrate diet. Obesity (Silver Spring). 2007;15(10):2470-2477.

22. Raynor HA, Jeffery RW, Phelan S, Hill JO, Wing RR. Amount of food group variety consumed in the diet and long-term weight loss maintenance. Obes Res. 2005;13(5):883-890

23. Raynor DA, Phelan S, Hill JO, Wing RR. Television viewing and long-term weight maintenance: results from the National Weight Control Registry. Obesity (Silver Spring). 2006;14(10):1816-1824.

24. Phelan S, Wyatt HR, Hill JO, Wing RR. Are the eating and exercise habits of successful weight losers changing? Obesity (Silver Spring). 2006;14(4):710-716.

25. Phelan S, Hill JO, Lang W, Dibello JR, Wing RR. Recovery from relapse among successful weight maintainers. Am J Clin Nutr. 2003;78 (6):1079-1084.

26. McGuire MT, Wing RR, Klem ML, Seagle HM, Hill JO. Long-term maintenance of weight loss: do people who lose weight through various weight loss methods use different behaviors to maintain their weight? Int J Obes Relat Metab Disord. 1998;22(6):572-577.

27. Butryn ML, Phelan S, Hill JO, Wing RR. Consistent self-monitoring of weight: a key component of successful weight loss maintenance. Obesity (Silver Spring). 2007;15(12):3091-3096.

28. Gorin AA, Phelan S, Wing RR, Hill JO. Promoting long-term weight control: does dieting consistency matter? Int J Obes Relat Metab Disord. 2004;28(2):278-281.

29. Gorin AA, Phelan S, Hill JO, Wing RR. Medical triggers are associated with better short- and long-term weight loss outcomes. Prev Med. 2004;39(3):612-616.

30. McGuire MT, Wing RR, Klem ML, Lang W, Hill JO. What predicts weight regain in a group of successful weight losers? J Consult Clin Psychol. 1999;67(2):177-185.

31. Klem ML, Wing RR, Lang W, McGuire MT, Hill JO. Does weight loss maintenance become easier over time? Obes Res. 2000;8(6):438-444.

32. Bickel WK, Moody LN, Koffarnus M, Thomas JG, Wing R. Self-control as measured by delay discounting is greater among successful weight losers than controls. J Behav Med. 2018;41(6):891-896.

33. Bond DS, Phelan S, Leahey TM, Hill JO, Wing RR. Weight-loss maintenance in successful weight losers: surgical vs non-surgical methods. Int J Obes (Lond). 2009;33(1):173-180.

34. Catenacci VA, Grunwald GK, Ingebrigtsen JP, et al. physical activity patterns using accelerometry in the National Weight Control Registry. Obesity (Silver Spring). 2011;19(6):1163-1170.

35. Catenacci VA, Odgen L, Phelan S, et al. Dietary habits and weight maintenance success in high versus low exercisers in the National Weight Control Registry. J Phys Act Health. 2014;11(8): 1540-1548.

36. Catenacci VA, Pan Z, Thomas JG, et al. Low/no calorie sweetened beverage consumption in the National Weight Control Registry. Obesity (Silver Spring). 2014;22(10):2244-2251.

37. Goldstein CM, Thomas JG, Wing RR, Bond DS. Successful weight loss maintainers use health-tracking smartphone applications more than a nationally representative sample: comparison of the National Weight Control Registry to Pew Tracking for Health. Obes Sci Pract. 2017;3 (2):117-126.

38. Klem ML, Wing RR, McGuire MT, Seagle HM, Hill JO. A descriptive study of individuals successful at long-term maintenance of substantial weight loss. Am J Clin Nutr. 1997;66(2):239-246.

39. Klem ML, Wing RR, Chang CC, et al. A case-control study of successful maintenance of a substantial weight loss: individuals who lost weight through surgery versus those who lost weight through non-surgical means. Int J Obes Relat Metab Disord. 2000;24(5): 573-579.

40. LaRose JG, Leahey TM, Hill JO, Wing RR. Differences in motivations and weight loss behaviors in young adults and older adults in the National Weight Control Registry. Obesity (Silver Spring). 2013;21(3): 449-453.

41. Lillis J, Thomas JG, Niemeier H, Wing RR. Internal disinhibition predicts 5-year weight regain in the National Weight Control Registry (NWCR). Obes Sci Pract. 2016;2(1):83-87.

42. Niemeier HM, Phelan S, Fava JL, Wing RR. Internal disinhibition predicts weight regain following weight loss and weight loss maintenance. Obesity (Silver Spring). 2007;15(10):2485-2494.

43. Phelan S, Wing RR, Raynor HA, Dibello J, Nedeau K, Peng W. Holiday weight management by successful weight losers and normal weight individuals. J Consult Clin Psychol. 2008;76(3):442-448.

44. Ross KM, Graham Thomas J, Wing RR. Successful weight loss maintenance associated with morning chronotype and better sleep quality. J Behav Med. 2016;39(3):465-471.

45. Shick SM, Wing RR, Klem ML, McGuire MT, Hill JO, Seagle H. Persons successful at long-term weight loss and maintenance continue to consume a low-energy, low-fat diet. J Am Diet Assoc. 1998; 98(4):408-413. 
46. Wyatt HR, Grunwald GK, Seagle HM, et al. Resting energy expenditure in reduced-obese subjects in the National Weight Control Registry. Am J Clin Nutr. 1999;69(6):1189-1193.

47. Klem ML, Wing RR, McGuire MT, Seagle HM, Hill JO. Psychological symptoms in individuals successful at long-term maintenance of weight loss. Health Psychol. 1998;17(4):336-345.

48. Thomas JG, Bond DS, Phelan S, Hill JO, Wing RR. Weight-loss maintenance for 10 years in the National Weight Control Registry. Am J Prev Med. 2014;46(1):17-23.

49. Wyatt HR, Grunwald GK, Mosca CL, Klem ML, Wing RR, Hill JO. Long-term weight loss and breakfast in subjects in the National Weight Control Registry. Obes Res. 2002;10(2):78-82.

50. Ostendorf DM, Melanson EL, Caldwell AE, et al. No consistent evidence of a disproportionately low resting energy expenditure in longterm successful weight-loss maintainers. Am J Clin Nutr. 2018;108(4): 658-666.

51. Ostendorf DM, Lyden K, Pan Z, et al. Objectively measured physical activity and sedentary behavior in successful weight loss maintainers. Obesity (Silver Spring). 2018;26(1):53-60.

52. Vieira PN, Silva MN, Coutinho SR, et al. Successful weight loss maintenance in Portugal and in the USA: comparing results from two National Registries. Rev Port Saude Publica. 2012;30(2):115-124.

53. Santos I, Vieira PN, Silva MN, Sardinha LB, Teixeira PJ. Weight control behaviors of highly successful weight loss maintainers: the Portuguese Weight Control Registry. J Behav Med. 2017;40(2): 366-371.

54. Vieira PN, Silva MN, Mata J, et al. Correlates of health-related quality of life, psychological well-being, and eating self-regulation after successful weight loss maintenance. J Behav Med. 2013;36(6): 601-610.

55. Mayr A, Gefeller O, Prokosch HU, Pirkl A, Frohlich A, de Zwaan M. Web-based data collection yielded an additional response bias-but had no direct effect on outcome scales. J Clin Epidemiol. 2012;65(9): 970-977.

56. Hubner C, Baldofski S, Crosby RD, Muller A, de Zwaan M, Hilbert A. Weight-related teasing and non-normative eating behaviors as predictors of weight loss maintenance. A longitudinal mediation analysis. Appetite. 2016;102:25-31.

57. Neumann M, Holzapfel C, Muller A, Hilbert A, Crosby RD, de Zwaan M. Features and trajectories of eating behavior in weight-loss maintenance: results from the German Weight Control Registry. Obesity (Silver Spring). 2018;26(9):1501-1508.

58. Icken D, Feller S, Engeli S, et al. Caffeine intake is related to successful weight loss maintenance. Eur J Clin Nutr. 2016;70(4): 532-534.

59. Soini S, Mustajoki P, Eriksson JG. Long-term weight maintenance after successful weight loss: motivational factors, support, difficulties, and success factors. Am J Health Behav. 2018;42(1):77-84.

60. Soini S, Mustajoki P, Eriksson JG, Lahti J. Personality traits associated with weight maintenance among successful weight losers. Am J Health Behav. 2018;42(6):78-84.

61. Soini S, Mustajoki P, Eriksson JG. Weight loss methods and changes in eating habits among successful weight losers. Ann Med. 2016;48 (1-2):76-82.

62. Yannakoulia M, Anastasiou CA, Karfopoulou E, Pehlivanidis A, Panagiotakos DB, Vgontzas A. Sleep quality is associated with weight loss maintenance status: the MedWeight study. Sleep Med. 2017;34: 242-245.

63. Karfopoulou E, Anastasiou CA, Hill JO, Yannakoulia M. The MedWeight study: design and preliminary results. Med J Nutrition Metab. 2014;201-210.

64. Karfopoulou E, Brikou D, Mamalaki E, Bersimis F, Anastasiou CA, Yannakoulia M. Dietary patterns in weight loss maintenance. Results from the MedWeight study. Eur J Nutr. 2017;56(3): 991-1002.
65. Karfopoulou E, Anastasiou CA, Avgeraki E, Kosmidis MH, Yannakoulia M. The role of social support in weight loss maintenance: results from the MedWeight study. J Behav Med. 2016;39(3): 511-518.

66. Brikou D, Zannidi D, Karfopoulou E, Anastasiou CA, Yannakoulia M. Breakfast consumption and weight-loss maintenance: results from the MedWeight study. Br J Nutr. 2016;115(12):2246-2251.

67. Anastasiou CA, Fappa E, Karfopoulou E, Gkza A, Yannakoulia M. Weight loss maintenance in relation to locus of control: the MedWeight study. Behav Res Ther. 2015;71:40-44.

68. Hartmann-Boyce J, Aveyard P, Koshiaris C, Jebb SA. Development of tools to study personal weight control strategies: OxFAB taxonomy. Obesity (Silver Spring). 2016;24(2):314-320.

69. Sardinha LB, Santos DA, Silva AM, et al. Prevalence of overweight, obesity, and abdominal obesity in a representative sample of Portuguese adults. PLoS One. 2012;7(10):e47883.

70. do Carmo I, Dos Santos O, Camolas J, et al. Overweight and obesity in Portugal: national prevalence in 2003-2005. Obes Rev. 2008;9(1): 11-19.

71. Schutz DD, Busetto L, Dicker D, et al. European practical and patientcentred guidelines for adult obesity management in primary care. Obes Facts. 2019; 12:40-66.

72. National Clinical Guideline C. National Institute for Health and Clinical Excellence: Guidance. In: Obesity: Identification, Assessment and Management of Overweight and Obesity in Children, Young People and Adults: Partial Update of CG43. London: National Institute for Health and Care Excellence (UK) Copyright (c) National Clinical Guideline Centre, 2014.; 2014.

73. Donnelly JE, Blair SN, Jakicic JM, Manore MM, Rankin JW, Smith BK. American College of Sports Medicine Position Stand. Appropriate physical activity intervention strategies for weight loss and prevention of weight regain for adults. Med Sci Sports Exerc. 2009;41(2): 459-471.

74. Horikawa C, Kodama S, Yachi Y, et al. Skipping breakfast and prevalence of overweight and obesity in Asian and Pacific regions: a meta-analysis. Prev Med. 2011;53(4-5):260-267.

75. O'Neil CE, Nicklas TA, Fulgoni VL 3rd. Nutrient intake, diet quality, and weight/adiposity parameters in breakfast patterns compared with no breakfast in adults: National Health and Nutrition Examination Survey 2001-2008. J Acad Nutr Diet. 2014;114 (12 Suppl):S27-S43.

76. van der Heijden AA, Hu FB, Rimm EB, van Dam RM. A prospective study of breakfast consumption and weight gain among U.S. men. Obesity (Silver Spring). 2007;15(10):2463-2469.

77. Sievert K, Hussain SM, Page MJ, et al. Effect of breakfast on weight and energy intake: systematic review and meta-analysis of randomised controlled trials. BMJ. 2019;364:142-53.

78. Kim JE, O'Connor LE, Sands LP, Slebodnik MB, Campbell WW. Effects of dietary protein intake on body composition changes after weight loss in older adults: a systematic review and meta-analysis. Nutr Rev. 2016;74(3):210-224.

79. Leidy HJ, Clifton PM, Astrup A, et al. The role of protein in weight loss and maintenance. Am J Clin Nutr. 2015;101(6):1320s-1329s.

80. Burke LE, Wang J, Sevick MA. Self-monitoring in weight loss: a systematic review of the literature. J Am Diet Assoc. 2011;111(1): 92-102.

81. Crain AL, Sherwood NE, Martinson BC, Jeffery RW. Mediators of weight loss maintenance in the Keep It Off Trial. Ann Behav Med. 2018;52(1):9-18.

82. Astell KJ, Mathai ML, Su XQ. Plant extracts with appetite suppressing properties for body weight control: a systematic review of double blind randomized controlled clinical trials. Complement Ther Med. 2013;21(4):407-416.

83. Pittler MH, Ernst E. Dietary supplements for body-weight reduction: a systematic review. Am J Clin Nutr. 2004;79(4):529-536. 
84. Ramage S, Farmer A, Eccles KA, McCargar L. Healthy strategies for successful weight loss and weight maintenance: a systematic review. Appl Physiol Nutr Metab. 2014;39(1):1-20.

85. Sciamanna CN, Kiernan M, Rolls BJ, et al. Practices associated with weight loss versus weight-loss maintenance results of a national survey. Am J Prev Med. 2011;41(2):159-166.

86. Kwasnicka D, Dombrowski SU, White M, Sniehotta F. Theoretical explanations for maintenance of behaviour change: a systematic review of behaviour theories. Health Psychol Rev. 2016;10(3): 277-296.

87. Weiss EC, Galuska DA, Kettel Khan L, Gillespie C, Serdula MK. Weight regain in U.S. adults who experienced substantial weight loss 1999-2002. Am J Prev Med. 2007;33(1):34-40.

88. Gilis-Januszewska A, Barengo NC, Lindstrom J, et al. Predictors of long term weight loss maintenance in patients at high risk of type 2 diabetes participating in a lifestyle intervention program in primary health care: the DE-PLAN study. PLoS One. 2018;13(3): e0194589.

89. Butryn ML, Thomas JG, Lowe MR. Reductions in internal disinhibition during weight loss predict better weight loss maintenance. Obesity (Silver Spring). 2009;17(5):1101-1103.

90. Mailloux G, Bergeron S, Meilleur D, D'Antono B, Dube I. Examining the associations between overeating, disinhibition, and hunger in a nonclinical sample of college women. Int J Behav Med. 2014;21(2): 375-384.

91. Will Crescioni A, Ehrlinger J, Alquist JL, et al. High trait self-control predicts positive health behaviors and success in weight loss. $J$ Health Psychol. 2011;16(5):750-759.

92. Faith MS, Flint J, Fairburn CG, Goodwin GM, Allison DB. Gender differences in the relationship between personality dimensions and relative body weight. Obes Res. 2001;9(10):647-650.
93. Jokela $M$, Hintsanen $M$, Hakulinen $C$, et al. Association of personality with the development and persistence of obesity: a metaanalysis based on individual-participant data. Obes Rev. 2013;14(4): 315-323.

94. Provencher V, Bégin C, Gagnon-Girouard M-P, Tremblay A, Boivin S, Lemieux S. Personality traits in overweight and obese women: associations with BMI and eating behaviors. Eat Behav. 2008;9(3): 294-302.

95. Lichtman SW, Pisarska K, Berman ER, et al. Discrepancy between self-reported and actual caloric intake and exercise in obese subjects. N Engl J Med. 1992;327(27):1893-1898.

96. Archer E, Pavela G, Lavie CJ. The inadmissibility of what we eat in America and NHANES dietary data in nutrition and obesity research and the scientific formulation of national dietary guidelines. Mayo Clin Proc. 2015;90(7):911-926.

97. Lassale C, Peneau S, Touvier M, et al. Validity of web-based selfreported weight and height: results of the Nutrinet-Sante study. J Med Internet Res. 2013;15(8):e152.

\section{SUPPORTING INFORMATION}

Additional supporting information may be found online in the Supporting Information section at the end of this article.

How to cite this article: Paixão C, Dias CM, Jorge R, et al. Successful weight loss maintenance: A systematic review of weight control registries. Obesity Reviews. 2020;1-15. https:// doi.org/10.1111/obr.13003 